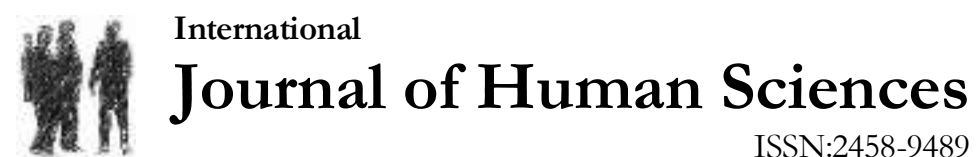

Volume 14 Issue 4 Year: 2017

\section{The role of physical environmental factors on university students' academic performance ${ }^{1}$}

\author{
Ayça Akdil Sönmez ${ }^{2}$ \\ Ali Talip Akpınar ${ }^{3}$
}

\begin{abstract}
Education and the level of educational development in a country constitute the basis for the social and economic development of that country. The importance of academic performance in a country, especially in higher education, can not be denied. It is therefore important to investigate factors that affect academic achievement in the positive or negative way. This paper aims to determine the factors influencing the academic performance of university students in terms of physical environment, including building design and conditions, campus layout and surrounding neighborhood.

This is an exploratory research in which qualitative research design is used. Statistical analyses such as regression, correlation and variance (ANOVA) are applied in order to analyze data. Since the whole survey population is made of the students of Aeronautics and Astronautics Faculty of Kocaeli University, there is no sampling method applied. Survey is performed on voluntary basis.

It was expected to reach the results supporting the main hypothesis of the research "physical environmental factors, such as building, campus layout and surrounding neighborhood, affect university students' academic performance". However, the findings are far apart from supporting the main hypothesis. It is found out that there is no relationship and no effect between academic performance and physical environmental factors.

Current study might be one of the pioneer studies regarding the university students' academic performance in context of aviation in Turkey. Despite of the fact that the students like to hold physical environment responsible for their academic failure, it is proven that there is no relation and no effect in between them. Of course, these results are weak in generality since the research is limited to only the Faculty of Aeronautics and Astronautics of Kocaeli University. Research needs to be replicated in different faculties and departments of different universities in order to ensure generalizability.
\end{abstract}

Keywords: Academic Performance; Physical Environment; Building Conditions; Campus Layout; Surrounding Neighborhood; University Students; Aeronautics and Astronautics; Aviation.

\footnotetext{
1 This paper, presented 11- 14 May 2017 in Denizli 'IV.International Euroasian Educational Research Congress”

2 Ph.D. Student, Kocaeli University, Institute of Social Sciences, aycaakdil@yahoo.com

3 Assoc. Prof., Kocaeli University, Faculty of Aeronoutics and Astronaoutics, Aviation Management, alitalip@yahoo.com
} 


\section{Introduction}

Education and the level of educational development in a country constitute the basis for the social and economic development of that country. The importance of academic performance in a country, especially in higher education, can not be denied. It is therefore important to investigate factors that affect academic achievement in the positive or negative way.

Performance is the accomplishment of a given task measured against preset known standards (Business Dictionary, 2017). These standards can be either cost or speed or accuracy, depending on the situation. Academic achievement, in other words academic performance, is the ability to meet the obligations of the courses in which the students are enrolled (Harvard University, 2017) and it is generally measured by GPA, the grade point average.

When it comes to the factors affecting the academic performance of university students, one can name various items starting from the individual factors -which refer to each student's unique combination of socioeconomic elements and ability-, teaching staff and methodology to environmental factors such as facilities, supportive activities, social atmosphere, etc. (Win \& Miller, 2005). Family conditions, such as socio-economic state and educational level of the parents, the number of sisters and brothers, and role-models of the students are influential on their academic success. Apart from these, there are two major influences coming from individual characteristics and educational factors. Students' own intelligence, interests, talents and motivation are as affective on their academic achievement as teaching environment, teaching programs and teaching staff. Waters, Marzano and McNulty summarized these factors under three main groups, namely school, teacher and student factors in their study in 2003 (Waters, Marzano \& McNulty, 2003). Despite of the fact that most of the teaching staff like to think it is their teaching methodology that makes the most difference to students' learning, teaching/learning environment is also recognized as a powerful influence (Wilkinson et al, 2013). For this reason, physical environmental factors constitute a valuable area for research.

Figure 1 Factors Affecting Academic Performance

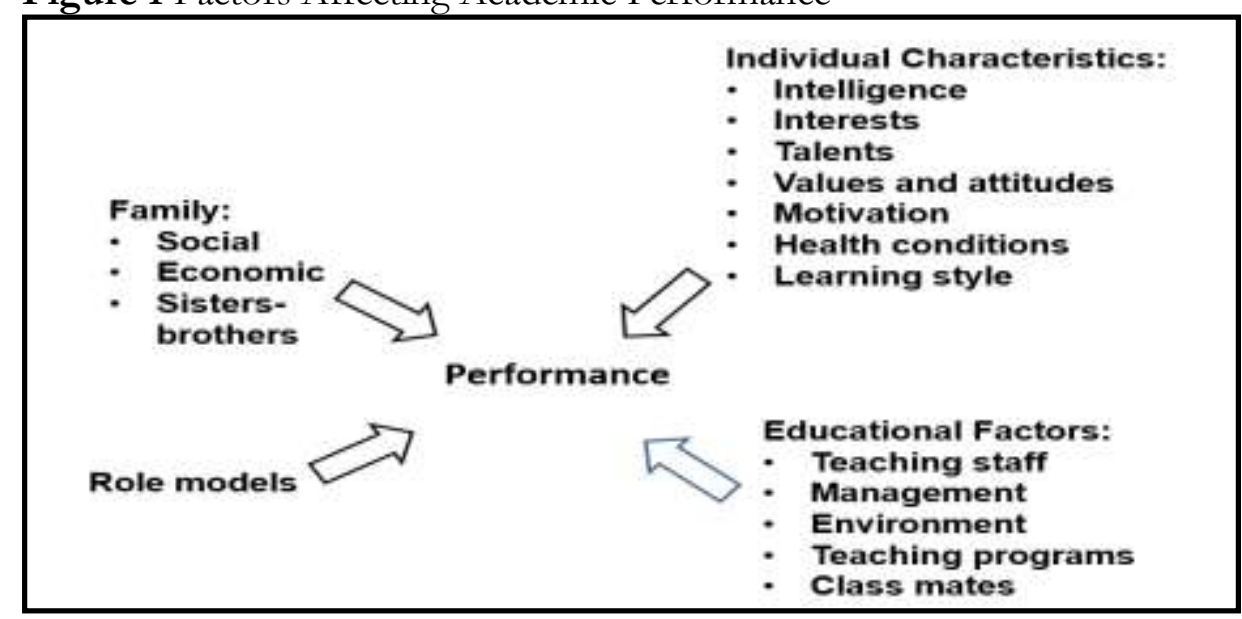

In many studies, it is proven that the factors related to the physical environment - such as design and condition of the school buildings, color of the classrooms, school facilities, locations and surroundings- have a significant effect on students' motivation and learning. Analyses suggest that factors such as the neighbourhoods where students live, or characteristics of the school that the students attend may be relevant as influences on how well a student performs (Manley \& Jonhston, 2014). For example, some studies have found that there has been a significant positive relationship between tree cover and reading performance, suggesting that initiatives aimed at increasing tree cover in student environments could support academic success (Hodson \& Sander, 2016). Hsu, Chiang and Liang suggest that, anyone who cares about science/engineering education should pay attention to how students learn and how physical and social environments can influence 
them. In this respect, different researchers have reached different results. For example, in a study dated 2002, it is found out that there is a strong positive relationship between overall building conditions and student achievement (Earthman, 2002). In another research made in year 2011, it is concluded that environmental factors affect male and female students differently (Zakaria, Kassim, Mohamad \& Buniyamin, 2011). In their study dated 2014, Manley and Johnston reached the conclusion that neighborhoods where students live and school characteristics may be relevant as influences on how well a student performs (Manley \& Jonhston, 2014). There are also some other studies with contradicting results, such as the research made by Wisneski, Ozogul and Bichelmeyer in year 2017. According to this study, student academic performance doesn't vary based on the learning environment and there was no significant difference in student learning across different learning environments (Wisneski, Ozogul \& Bichelmeyer, 2017). Even though many studies are made on the same issue, only a few of these studies are relevant with higher education and university students. In this respect, current study aims to determine the factors influencing the academic performance of university students in terms of physical environment, including building design and conditions, campus layout and surrounding neighborhood.

\section{Method}

Research design. This is an exploratory research, the population of which is made up of the students attending three different programs in the Faculty of Aeronautics and Astronautics at Kocaeli University. These programs are Civil Aviation Transportation Management, Aircraft Mainframe and Powerplant Maintenance and Aircraft Avionics. Through literature review and based on two sample studies, a survey questionnaire is developed in which there are three subtitles, namely demographics, details regarding physical environment (building conditions, campus layout and surrounding neighborhood) and additional comments.

Main hypothesis of the study is stated as follows:

H0: "Physical environmental factors affect university students' academic performance."

Physical environmental factors refer to building conditions, campus layout and surrounding neighborhood, so the main hypothesis is divided into three sub-hypotheses as shown below, so that they can be tested easily:

H1: "Building conditions affect university students' academic performance."

H2: "Campus layout affects university students' academic performance."

H3: "Surrounding neighborhood affects university students' academic performance."

As the research was made in the Faculty of Aeronautics and Astronautics at Kocaeli University, this study tends to be one of the pioneer studies regarding the university students' academic performance in context of aviation in Turkey.

Research sample. Since the whole survey population is made of Civil Aviation Transportation Management, Aircraft Mainframe and Powerplant Maintenance and Aircraft Avionics students, there is no sampling method applied. Survey is performed on voluntary basis. Ongoing data collection and analysis process were estimated to be completed by the end of February 2017.

Research instrument and procedure. Civil Aviation Transportation Management, Aircraft Mainframe and Powerplant Maintenance and Aircraft Avionics students of Kocaeli University were requested to answer the questions on a survey questionnaire, in which there were three subtitles, namely demographics, details regarding physical environment and additional comments. In the first part demographic data, such as age, sex, gender, etc., are collected. Second part is the most important part of the questionnaire, because it is referring to physical environmental factors and in the third part some additional information regarding the students' satisfaction and preferences were requested. 
Figure 2 Survey Design and Methodology

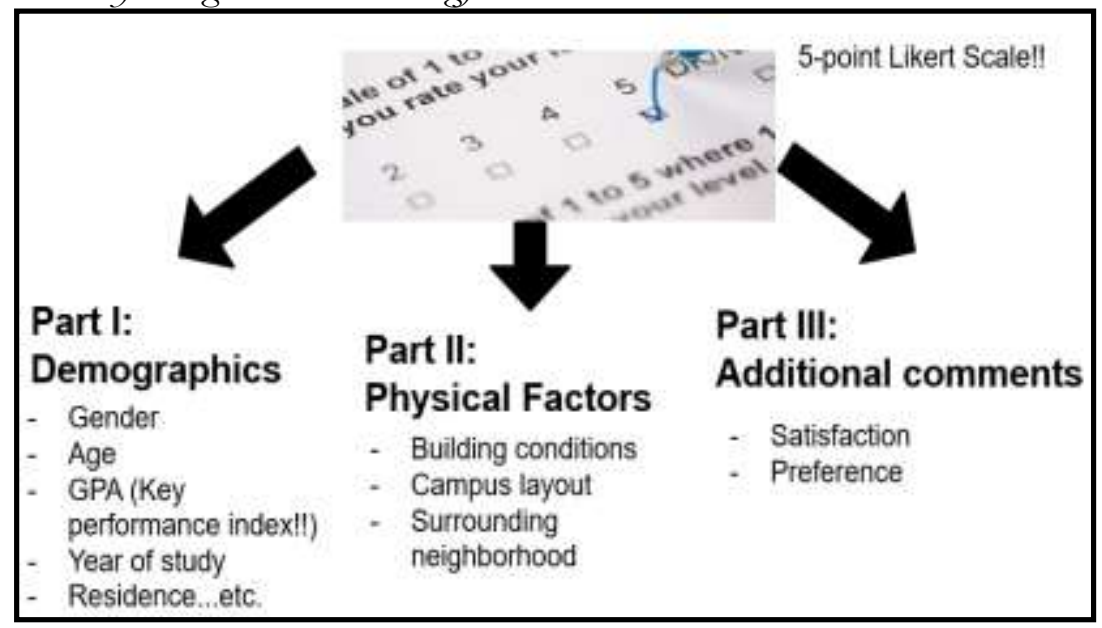

Relevant data were collected using the above mentioned survey questionnaire consisting of open- and closed-ended questions, some of which are supposed to measure an interval level (e.g. 5point Likert scale). As the Key Performance Index, the Cumulative Grade Point Average (GPA) was preferred.

Data analysis. Descriptive statistics, mean and standard deviation, as well as the correlation matrixes were used within the analysis. Also, analysis of variance (ANOVA) was applied in order to answer the research. Participation in the research was on voluntary basis, so none of the students were forced to fill in the questionnaire. Total population was made up of 1033 students, but due to the OJT-Program (on-the-job-training program) of the technical departments, 150 students were missing in the campus.

In the first part, the students were asked to provide demographic details such as their age, sex, GPA (grade point average), year of study, residence location and etc. In the second part, the students included their levels of agreement to the given statements on a 5-point likert scale. In the third part, it was aimed to obtain student evaluations regarding some statements on their preference and satisfactions.

Based on the physical environment, it is aimed to determine the importance of each factor for each "year of study"; and to obtain students' evaluations regarding the items relevant with these factors. CATM refers to Civil Aviation Transportation Management; AMPM refers to Aircraft Mainframe and Poweplant Maintenance; and AAV refers to Aircraft Avionics departments.

\section{Results}

Results-part I. Figure 3 contains the participation rates of three departments. The highest participation rate belongs to CATM and other two technical departments are at 15\% participation rate, but in fact these rates should be around 18\% because the population is not actually 1033 students; 150 students were missing because of their OJT-Programs. 
Akdil Sönmez, A., \& Talip Akpınar, A. (2017). Title in article's language. Journal of Human Sciences, 14(4), 4241-4250. doi:10.14687/jhs.v14i4.5025

Figure 3 Participation Details

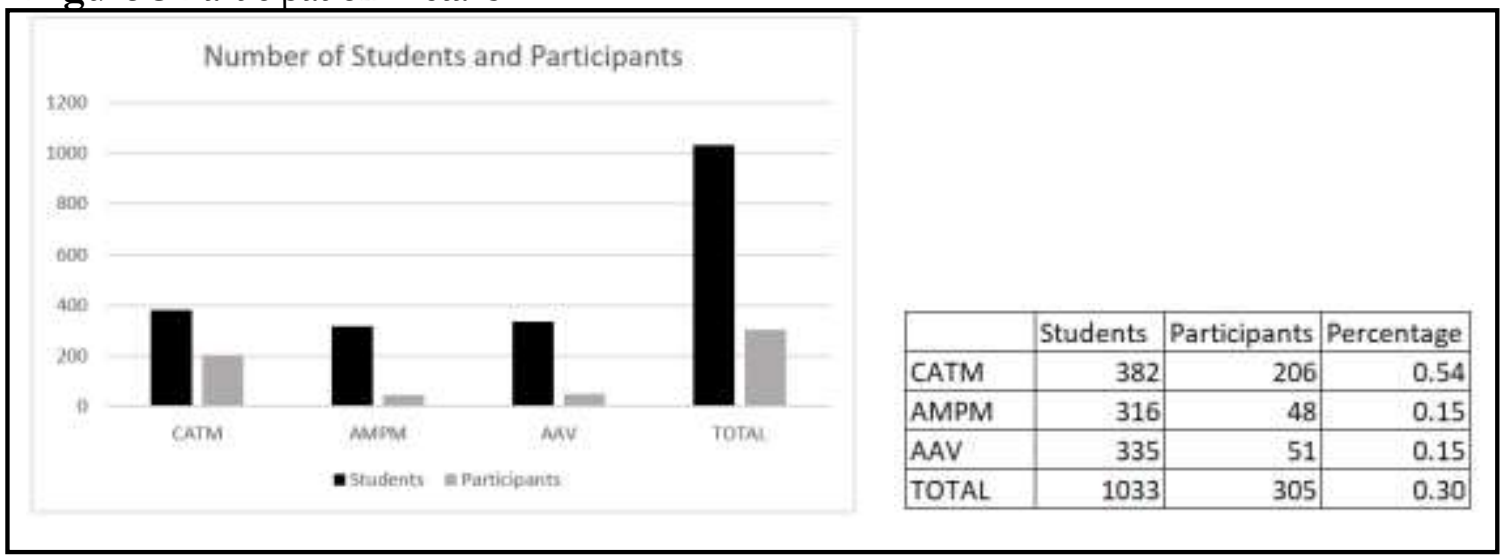

Regarding the statistics about gender, $32 \%$ belongs to females, while $68 \%$ belongs to males and this reflects the real situation, since there is fewer female students at the Faculty of Aeronautics and Astronautics.

Figure 4 Details Regarding Gender

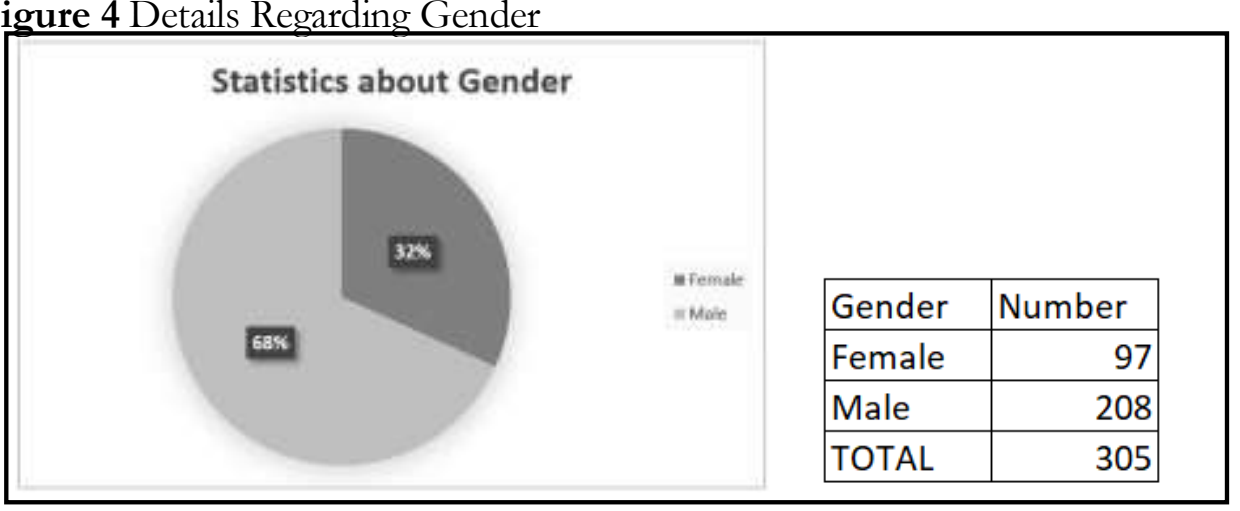

The vast majority of the students are between 18 and 23 years old. The remaining ones starting from 24 to 35 can be evaluated under one group. The age-missing students can also be counted on this remaining group.

Figure 5 Distribution of Ages

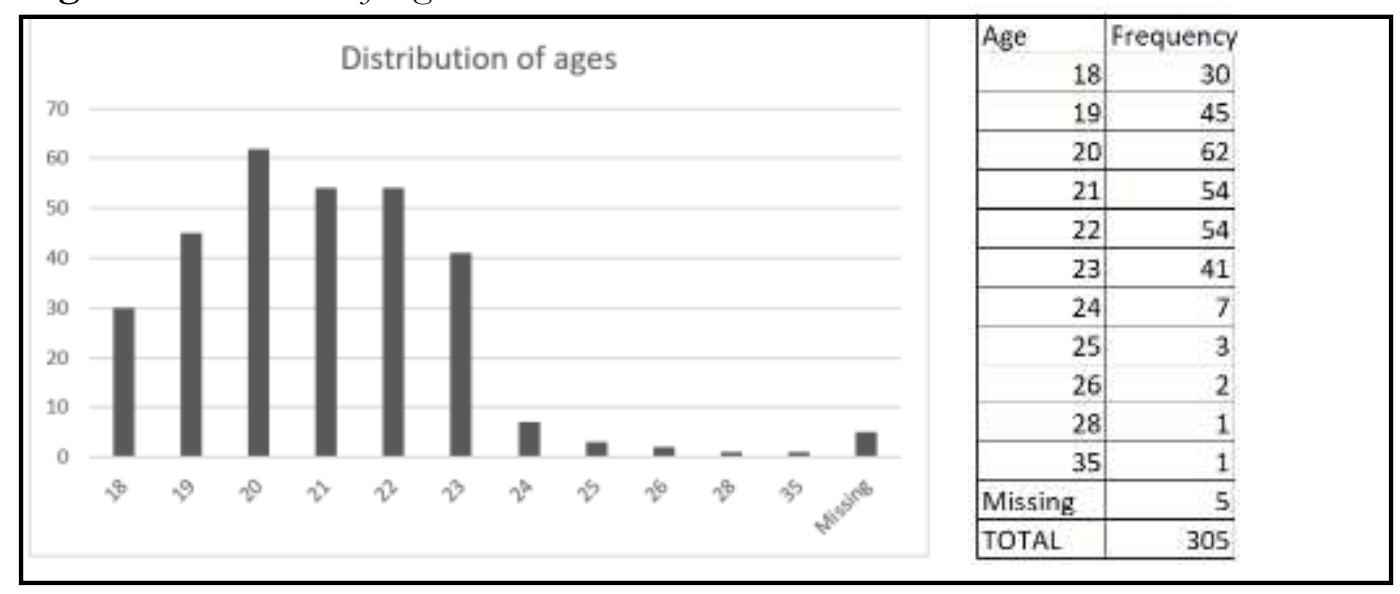

The majority of the participants belong to the students from first year of study. This doesn't mean that freshmen are more interested in the research, but shows that their attendance rate is higher than the others. 
Akdil Sönmez, A., \& Talip Akpınar, A. (2017). Title in article's language. Journal of Human Sciences, 14(4), 4241-4250. doi:10.14687/jhs.v14i4.5025

Figure 6 Frequencies According to The Year of Study

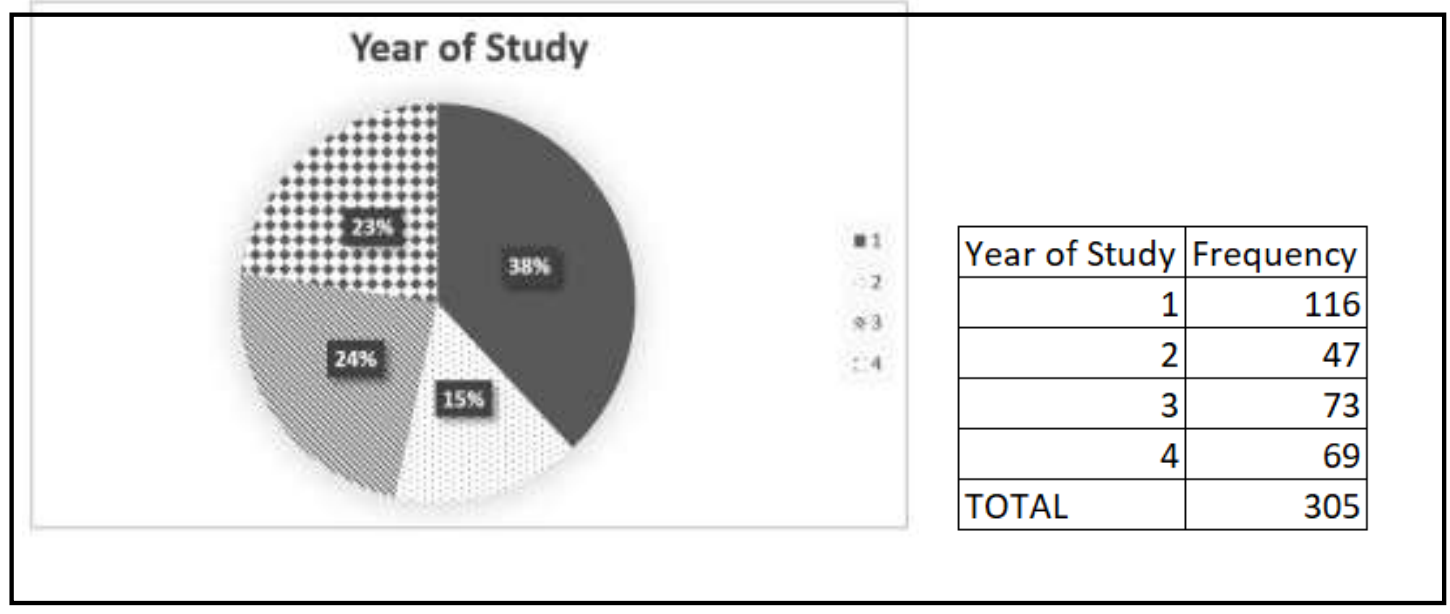

Regarding year of study, there are two students from fifth class. This data are not taken into consideration, since these students are the ones who have prolonged their study periods and they are counted with the seniors $(67+2=69$ students totally). The highest grades belong to the second classes, while the lowest grades belong to the fourth classes. Since the sigma value is smaller than 0,05 , it can be said that GPAs differ according to year of study. In other words, GPA is affected by the year of study.

Table 1 GPAs According to Year of Study

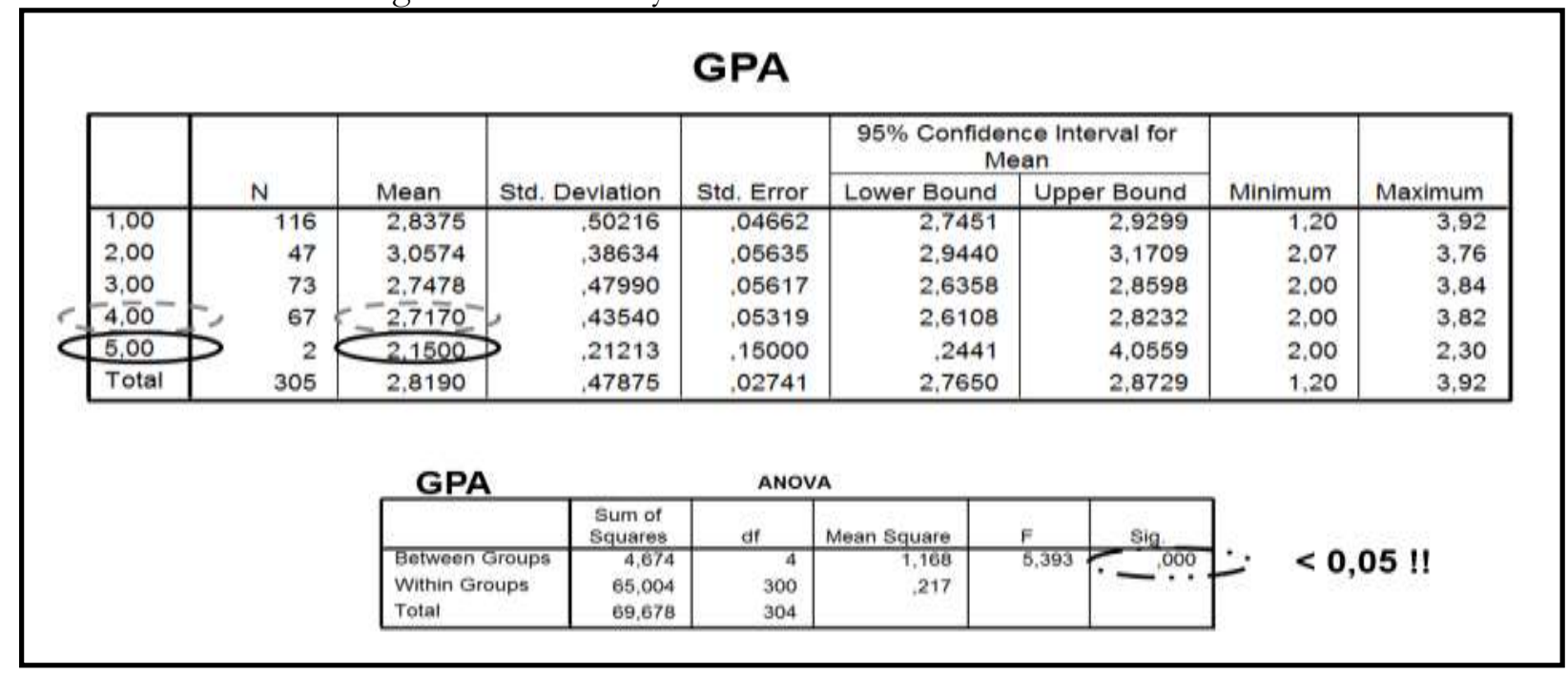

As regards the study program, the lowest grades belong to AMPM, while the highest grades are targeted by CATM. The sigma value is again smaller than 0,05. It means, the GPAs differ according to the study program. 
Akdil Sönmez, A., \& Talip Akpınar, A. (2017). Title in article’s language. Journal of Human Sciences, 14(4), 4241-4250. doi:10.14687/jhs.v14i4.5025

Table 2 GPAs According to Departments/Study Programs

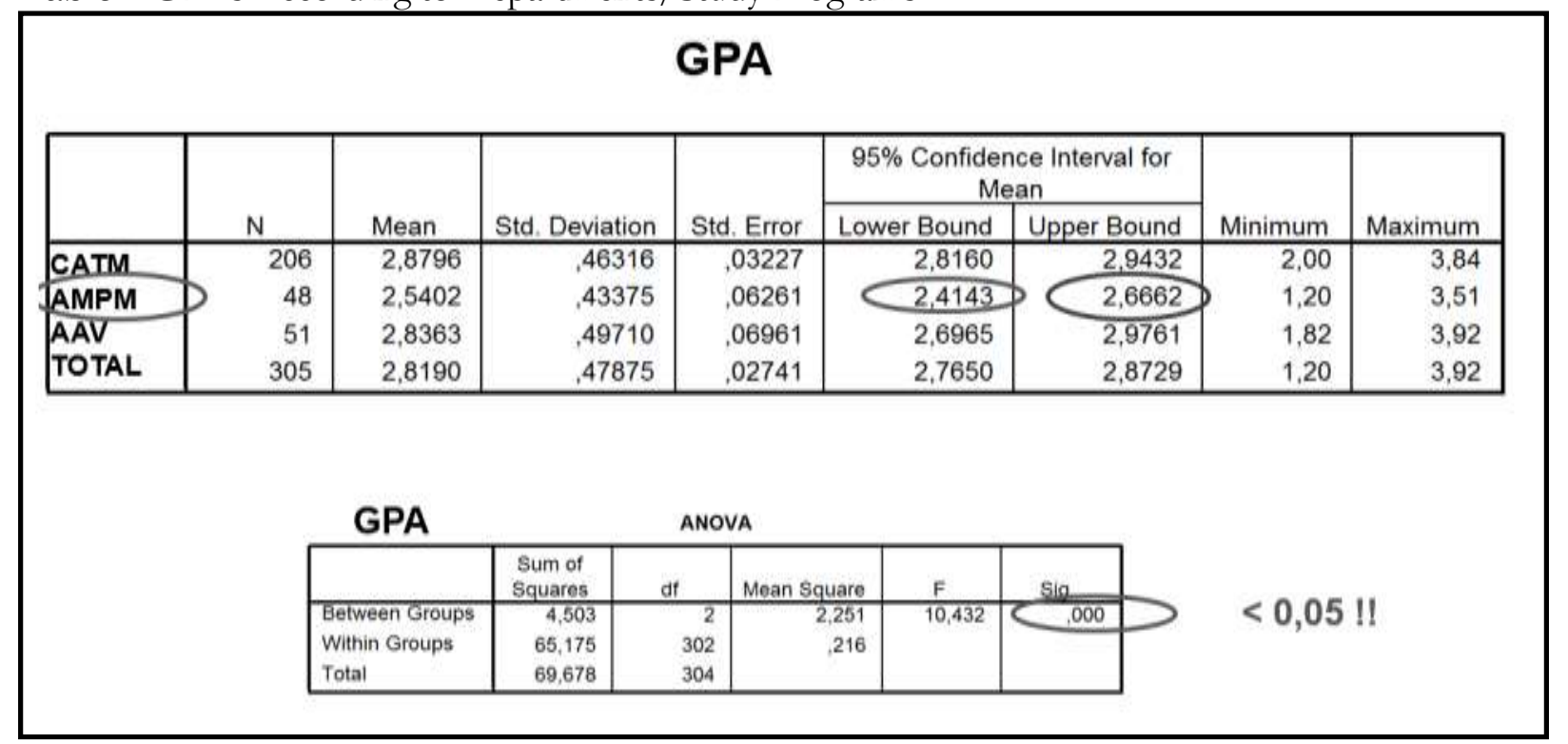

There is no relevance between the GPAs and residence location. Arslanbey is the closest area and Istanbul is the furthest area, but the residence location of the student makes no significant difference to GPAs. Besides, sigma value is bigger than 0,05 and this shows that there is no affect of the residence location on the GPAs of the students.

Table 3 GPAs According to Residence Locations

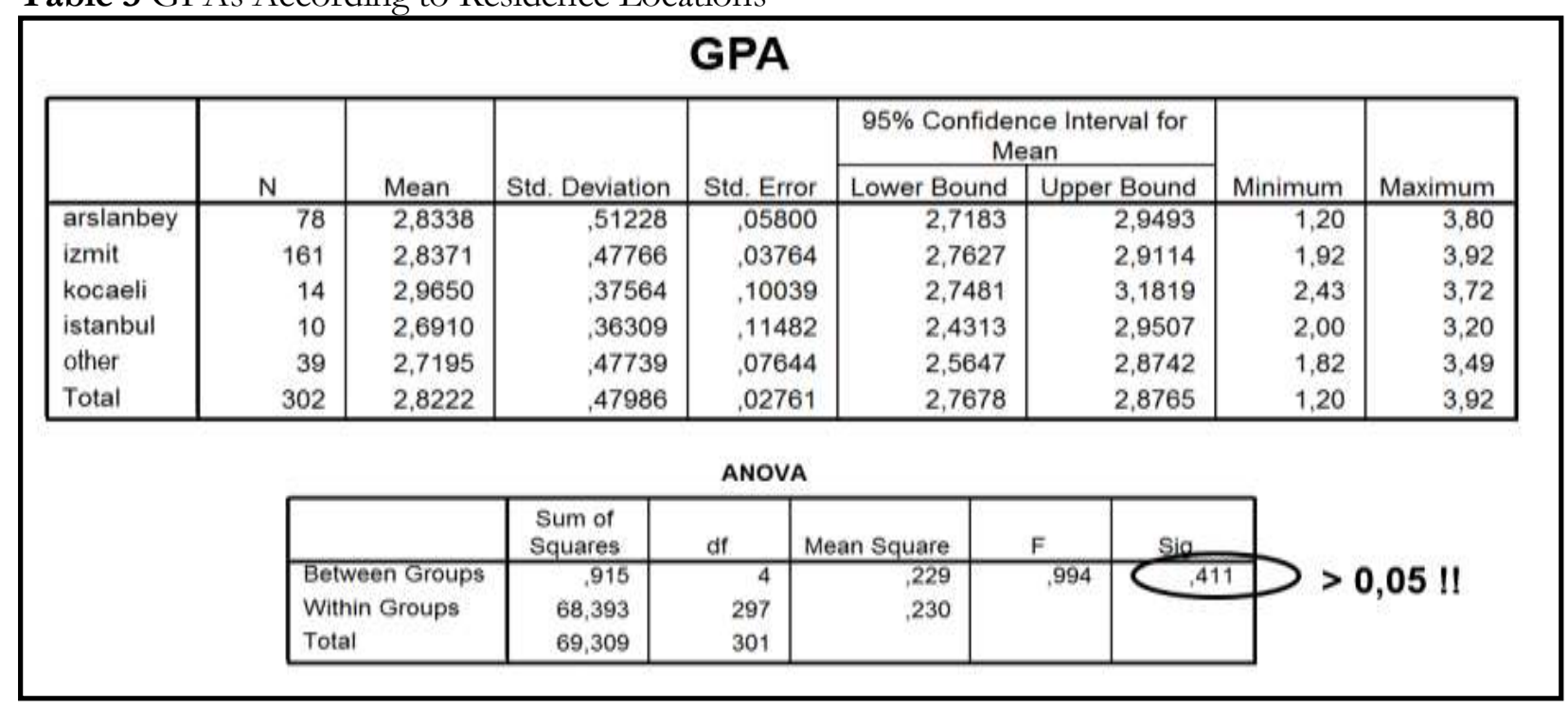

Results-part II. In the second part, the relationships and effects between GPAs and physical environmental factors are handled.

The correlation matrix below shows the relationships between GPAs, building conditions, campus layout and surrounding neighborhood. As it is clearly seen, the correlation values between the GPA and physical environmental factors are very small, and even for the building conditions and campus layout these values are negative (-,093 and -,016). Under these circumstances it can be said that there is no relationship between physical environmental factors and academic performance. 
Results-part III. In the third part of the questionnaire the following statements regarding the students' evaluations about their preferences and satisfaction of the departments, in which they are studying, take part:

D1: 'I am satisfied with the department where I study.'

D2: 'If I were to take the university exam again, I would prefer the same department.'

D3: 'If I were to take the university exam again, I would prefer the same department at the same university.'

Student evaluations are taken based on a 5-point likert scale, where 1 represents 'strongly disagree', 2 'disagree', 3 'have no idea/don't know', 4 'agree' and 5 'strongly agree'. As shown in the following table, academic performance is related with D1 and D2. This means, as long as the students are satisfied with the departments where they study, their GPAs tend to increase. The same effect goes for the relationship between D1 and D2, which means, as long as the students are satisfied with the departments where they study, their likelihood for choosing the same department increases.

Table 6 Relationships Between GPAs and Satisfaction Levels and Preferences

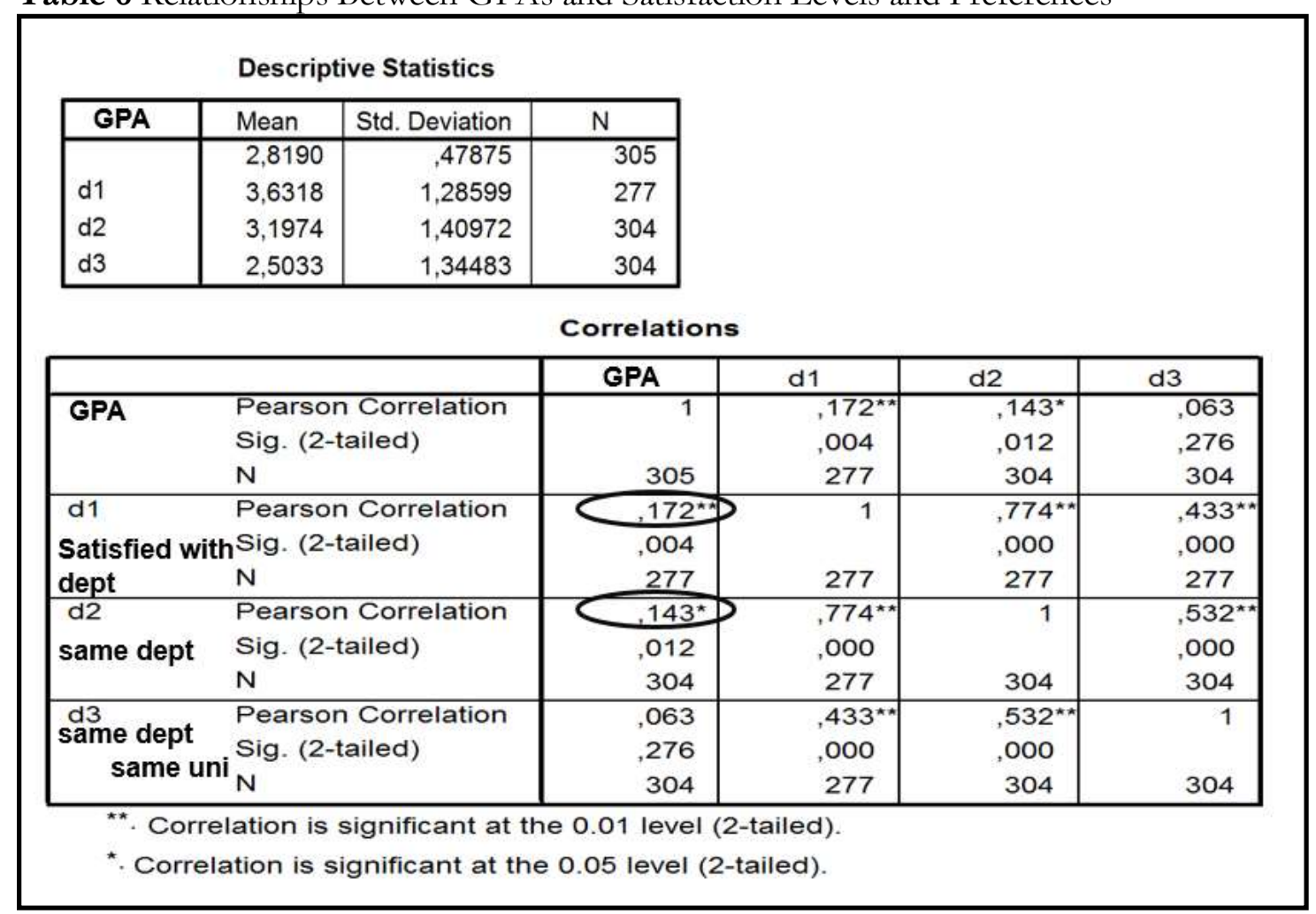

\section{Discussion and Conclusion}

In the current study, it was expected to reach the results supporting the main hypothesis of the research "physical environmental factors affect university students' academic performance". Despite of the fact that the students like to hold physical environment responsible for their academic failure, it is proven that there is no relation and no effect in between them. Of course, these results are weak in generality since the research is limited to only the Faculty of Aeronautics and Astronautics of Kocaeli University. Besides, the participation was on voluntary basis and whole population of the students were not reached. Due to the On-The-Job Training program of technical departments, 150 of 1033 students were already missing. As a result of this, research needs to be replicated in different faculties and departments of different universities in order to ensure generalizability. 
Still, this study might be one of the pioneer studies regarding the university students' academic performance in context of aviation in Turkey.

Compared to previous studies, in this study, it is aimed to determine the factors influencing the academic performance of university students in terms of physical environment, including building design and conditions, campus layout and surrounding neighborhood and to find out if there is a relationship and affect between academic performance and physical environmental factors using statistical methods such as correlation and variance analysis (ANOVA).

Within the study, the grade point average (GPA) is selected as the key performance indicator, as it is an objective sign of academic success.

Even though the physical environmental factors are said to be important influencers of academic success, it is found out that academic performance (GPA), building conditions, campus layout and surrounding neighborhood are not related with eachother. There is also no affect of these physical environmental factors on the students' academic performance. Some other factors, such as the students' satisfaction level and preference are found to be affective on the GPAs. As long as the students are satisfied with the departments where they study, their GPAs tend to increase, and as long as the students are satisfied with the departments where they study, their likelihood for choosing the same department increases. Also the GPAs differ according to the year of study and the department, where the students attend. The highest grades belong to the second classes, while the lowest grades belong to the fourth classes; and as regards the study program, the lowest grades belong to AMPM, while the highest grades are targeted by CATM. No affect is identified regarding the residence location on the academic performance in the current study.

\section{References}

Business Dictionary (2017). http://www.businessdictionary.com/definition/performance.html

Earthman, G. I. (2002). School Facility Conditions and Student Academic Achievement

(Document wws-rr008-1002), UCLA's Institute for Democracy, Education \& Access, available at www.ucla-idea.org.

Harvard University (2017).

http://static.fas.harvard.edu/registrar/ugrad_handbook/current/chapter2/academic_performance. $\underline{\mathrm{html}}$

Hodson, C. B., \& Sander, H. A. (2016). Green-urban landscapes and school-level academic perfomance, in Landscape and Urban Planning, 160, pp. 16-27, available at http://dx.doi.org/10.1016/j.landurbplan.2016.11.011.

Hsu, M-C., Chiang, C, \& Liang, C. (2014). The mediator effects of imagination between learning environment and academic performance: a comparison between science and engineering majors, in Int. J Technol Des Edue, 24: 413-436.

Manley, D., \& Johnston, R. (2014). School, Neighbourhood, and University: The Geographies of Educational Performance and Progression in Enland, in Appl. Spatial Analysis, 7:259-282.

Waters, Marzano \& McNulty. (2003). Balanced Leadership: What 30 years of research tells us about the effect of leadership on student achievement, http:// files.eric.ed.gov/fulltext/ED481972.pdf

Wilkinson, T. J., Ali, A. N. , Bell, C. J., Carter, F.A., Frampton, C. M., \& McKenzie, J. M. (2013). The impact of learning environment disruption on medical student performance, in Medical Education, 47, pp. 210-213.

Win, R., \& Miller, P. W. (2005). The Effects of Individual and School Factors on University Student's Academic Performance, in The Australian Economic Review, vol. 38, no.1, pp. 118.

Zakaria,Z., Kassim, R.A., Mohamad, A., \& Buniyamin, N. (2011). The Impact of Environment on Engineering Students' Academic Performance: A Pilot Study, 3rd International Congress on Engineering Education (ICEED). 